\title{
Paulo Fernando Cidade de Araújo: a unanimidade como homem de ciência, construtor institucional e amigo ${ }^{1,2}$
}

\author{
Amílcar Baiardi ${ }^{3}$, Geraldo Barros ${ }^{4}$, Humberto Spolador ${ }^{5}$, \\ Léo da Rocha Ferreira ${ }^{6}$ e Pery Francisco Assis Shikida ${ }^{7}$
}

\begin{abstract}
"Duas coisas sempre me impressionaram e procuro valorizar: os exemplos de pessoas e a missão social das instituições. Valorizar as instituições é algo fundamental e na Esalq isso se faz muito bem, unindo educação, agricultura e economia. Além disso, muitos são os bons exemplos de pessoas que encontrei e com elas convivi e até hoje convivo na Luiz de Queiroz: professores, ex-alunos, alunos e funcionários."
\end{abstract}

Paulo Cidade

\section{Introdução}

O dia 13 de dezembro de 2016 ficará na história da Sociedade Brasileira de Economia, Administração e Sociologia Rural, Sober, como a data na qual o conjunto de sua comunidade registrou uma perda humana de grande significado. Nesse dia, uma terça-feira, aos 84 anos, faleceu o associado e admirado colega Paulo Fernando Cidade de Araújo. Seu sepultamento se deu na manhã seguinte, 14 de dezembro, no Cemitério da Vila Rezende, em Piracicaba, cidade na qual viveu intensamente várias experiências profissionais e que lhe acolherá pela eternidade. Paulo Cidade era viúvo de Maria Scassa Araújo, teve dois filhos, Ruy Araújo Netto e Paula Scassa Araújo, ambos casados, que lhe deram netos.

1. Data de submissão: 6 de maio de 2017. Data de aceite: 22 de outubro de 2017.

2. DOI: http://dx.doi.org/10.1590/1234-56781806-94790560210

3. Universidade Católica do Salvador/Universidade Federal da Bahia, Salvador, Bahia, Brasil. E-mail: amilcarbaiardi@uol.com.br

4. Escola Superior de Agricultura Luiz de Queiroz, Universidade de São Paulo, Piracicaba, São Paulo, Brasil. E-mail: gscbarro@usp.br

5. Escola Superior de Agricultura Luiz de Queiroz, Universidade de São Paulo, Piracicaba, São Paulo, Brasil. E-mail: hspolador@usp.br

6. Universidade do Estado do Rio de Janeiro, Rio de Janeiro, Brasil. E-mail: leorocha@uerj.br

7. Universidade Estadual do Oeste do Paraná, Toledo, Paraná, Brasil. E-mail: peryshikida@hotmail.com 
348 - Paulo Fernando Cidade de Araújo: a unanimidade como homem de ciência, construtor institucional e amigo

Dada à multidimensionalidade humana e acadêmica de Paulo Cidade e ao fato de ter estado presente em várias instituições ao longo de sua vida profissional, um grupo de colegas associados à Sober deliberou por construir um texto coletivo homenageando-o, o qual refletisse sua trajetória, mediante testemunhas dos mesmos. O presente texto, então, constitui-se uma narrativa organizada que tenta ser linear e diacrônica com um segmento sincrônico, que é o tempo da presença dele na Sober, momento esse que coincide ou se superpõe a quase todos os outros períodos.

O texto é uma abordagem em história contemporânea, mais precisamente em história contemporânea da ciência, com foco em protagonismos acadêmico e profissional de homens de ciência, no caso atuando na grande área de ciências sociais aplicadas. A abordagem se inspira no princípio que, segundo Graham (2007), a história da ciência é melhor estudada em um grupo em que haja especialistas em uma variedade de disciplinas, incluindo sociólogos, cientistas políticos, psicólogos, professores de engenharia e ciência, economistas e historiadores. O método pautou-se pelo procedimento internalista e inspirado no movimento intelectual "La nouvelle histoire" $\mathrm{e}$ as fontes foram predominantemente depoimentos identificados, livros e periódicos impressos e sites institucionais (BAIARDI, 2007; BAIARDI, 2014).

\section{Da Amazônia para o Sudeste}

Paulo Cidade, como era mais conhecido, nasceu em 7 de março de 1932 no município de Porto Velho, então pertencente ao estado do Amazonas, que atualmente é capital do estado de Rondônia. Pertence a uma plêiade de nortistas que deixaram o torrão natal para se aventurar no Sudeste do Brasil. Até a década de 1960, adolescentes nortistas tinham no imaginário deixar a Amazônia para estudar ou conseguir um emprego e os deslocamentos, com frequência, implicavam sacrifícios familiares, se dando por navio de cabotagem que demorava semanas, sendo as cartas o único meio de comunicação acessível, e que também demoravam semanas.

Nosso homenageado ainda muito jovem foi morar no Rio de Janeiro, tendo começado a trabalhar aos 17 anos, no Instituto de Aposentadoria e Pensão dos Comerciários (IAPC). Seu pai, Ruy Araújo, pernambucano de nascimento, viera para Manaus aos quatro anos de idade, levado pelos genitores, o jurista Francisco Pedro de Araújo Filho e a senhora Francelina Barbosa de Araújo. Ruy Araújo, nome também dado a um filho de Paulo Cidade, graduou-se em Direito, contraiu matrimônio e teve três filhos com Helena Cidade de Araújo, um deles Paulo Fernando Cidade de Araújo. Trabalhou nos Correios durante 13 anos e posteriormente foi promotor de justiça com atuação em várias comarcas do interior do Amazonas. Foi também secretário de Segurança Pública do Amazonas e deputado federal por esta unidade da Federação.

O fato de o pai ter sido deputado federal pode explicar as razões para Paulo Cidade de Araújo ter ido residir no Rio de Janeiro, então capital da República, e lá cursado a Escola Nacional de Agronomia, ENA, pois, na metade do século passado essa escola de agronomia, que se situava ao longo da estrada Rio de Janeiro - São Paulo, à altura do km 47, ao lado da Escola Superior de Agricultura e Veterinária, Esav, de Viçosa e da Escola Superior

8. Movimento renovador denominado "Escola dos Annales", iniciado por grupo de historiadores que lançou a 'Revista dos Annales' (1929), na França, composto por: Lucien Febvre, Marc Bloch, Fernand Braudel, Georges Duby, Jacques Le Goff e Emmanuel Le Roy Ladurie. 
de Agricultura Luiz de Queiroz, Esalq, localizada em Piracicaba, destacavam-se como centros de ciências agrárias. ${ }^{9}$

Paulo Cidade ingressou a ENA em 1953, graduando-se em 1956 e durante todo este período foi bolsista da Superintendência do Ensino Agrícola e Veterinário Ministério da Agricultura, Seav/MA. Tendo sido despertado pelo interesse em aprofundar estudos de economia, muito comum entre engenheiros agrônomos, e inexistindo à época pós-graduação stricto sensu neste campo do saber, em 1959 ingressou na Faculdade de Economia e Finanças do Rio de Janeiro, FEF-RJ, tendo se graduado bacharel em ciências econômicas em 1963. Na sua graduação, realizada à noite visto que já trabalhava como engenheiro agrônomo, teve como colega o engenheiro Mario Henrique Simonsen, eminente economista e futuro ministro. Nesse período realizou o curso de Desenvolvimento Econômico da Comissão Econômica para a América Latina (Cepal), tendo como professores Celso Furtado, Osvaldo Sunkel e Alberto Fracchia.

Ainda nesse primeiro período no Rio de Janeiro, Paulo Cidade alude a uma experiência pessoal muito curiosa que teria sido um encontro com o presidente Juscelino Kubitschek de Oliveira em Turim, Itália, em decorrência de ter presidido a Confederação Brasileira de Desportos Universitários (CBDU) e ter ido representar o Brasil nos Jogos Universitários Mundiais realizados naquela cidade no norte da Itália.

Seu primeiro emprego foi como engenheiro agrônomo na Divisão de Engenharia Rural, do Ministério da Agricultura, e de lá foi trabalhar no programa de crédito rural do Banco da Lavoura de Minas Gerais, onde foi despertado pelo tema que se tornou objeto de pesquisas e trabalhos acadêmicos posteriores no programa de crédito rural.

Antes de 1964 teve uma breve passagem pela Divisão de Assistência Técnica Especializada, Date, da Secretaria de Agricultura do Estado de São Paulo, em Campinas. Essa proximidade com Piracicaba e com a Esalq ensejou, no início de 1964, um convite para dar palestra sobre desenvolvimento econômico, na então 7aㅡ Cadeira, de Economia Rural. A repercussão dessa palestra levou o então professor responsável pela disciplina, Érico da Rocha Nobre, a convidá-lo para ministrar aulas, o que se concretizou com Paulo Cidade tornando-se professor assistente já no segundo semestre desse mesmo ano. ${ }^{10}$

\section{O professor Paulo Cidade na sua primeira passagem pela Esalq: mestrado, doutorado e livre docência}

Desde agosto de 1964, o engenheiro agrônomo e economista Paulo Fernando Cidade de Araújo atuou como docente e pesquisador na Esalq/USP, tendo definido claramente sua linha de pesquisa desde o início de sua carreira: o crédito rural e o desenvolvimento da agricultura. Já no biênio 1966/67 desenvolveu programa de pós-graduação na Ohio State University, nos Estados Unidos, ocasião em que preparou a dissertação "An Economic Study of the Demand for Rural Credit", sob orientação de Norman Rask. Obtinha, assim, seu título de mestrado em economia agrícola. Esse trabalho fincava as raízes de uma atuação profissional daquele que seria o maior especialista em crédito rural no Brasil. Retornando

9. Informações gentilmente prestadas por Alfredo Kingo Oyama Homma, membro legendário da Sober, pesquisador em ciências agrárias e em história regional.

10. A 7a Cadeira - criada em 1912 e até 1937 atuando sob a responsabilidade do Professor Catedrático Tarcísio de Magalhães, com o escopo de economia rural, legislação agrária e contabilidade agrícola - estava na época sob a responsabilidade do Professor Catedrático Érico da Rocha Nobre. Somente em 1972, quando Joaquim J. C. Engler substituiu Érico Nobre, é criado o Departamento de Economia, Administração e Sociologia, LES. 
ao Brasil, imediatamente lançou-se à preparação de sua tese de doutorado em economia aplicada no biênio 1968/69, "Produtividade do Crédito Rural na Agricultura", sob orientação de Érico da Rocha Nobre, defendida em co-tutela na Ohio State University. Em 1981, apresentaria sua tese de livre-docência "Análise da Política de Crédito Rural no Brasil".

Geraldo Sant'Ana de Camargo Barros relata que ter tido em 1969 Paulo Cidade como professor na disciplina "Análise Econômica", oferecida então no quarto ano de engenharia agronômica, foi uma experiência que iria marcar sua vida e o início de sua carreira de professor e pesquisador. Destaca Geraldo que lhe chamou atenção, desde o princípio, a dedicação ímpar do Prof. Paulo à referida disciplina. Em todas as aulas era distribuído a cada aluno um texto especialmente preparado para leitura e discussão. Na parte expositiva, o Prof. Paulo usava o que se chamava de "álbum seriado", um conjunto de folhas cartolina (com definições, conceitos, ilustraçóes) preso a um suporte de madeira, sobre o qual as folhas já apresentadas eram dobradas. Segundo relato, Paulo Cidade circulava pela classe conversando simpaticamente com os alunos sobre o assunto do dia ou sobre alguma experiência prática. Falava ainda de suas viagens frequentes e dos inúmeros contatos que estabelecia nessas oportunidades. Seus exemplos de aplicação da teoria econômica sempre se referiam a questões de interesse de uma plateia de jovens, cuja atenção se concentrava na fala do mestre: a plateia ora mostrava feições sérias, ora ria desabridamente.

Com essa conduta, de acordo com Geraldo S. Camargo Barros, o Prof. Paulo atraía os interesses dos alunos para a área de ciências sociais aplicadas, em especial, a economia. Boa parte dos alunos dirigia-se, a seguir, para a especialização em economia no quinto ano do curso; os melhores desses inscreviam-se no programa de mestrado em economia agrária, recentemente implantado na Esalq. Incontáveis foram as vezes em que o Prof. Paulo foi homenageado pelos formandos da escola.

Paulo Cidade tomava frequentemente iniciativas inovadoras no Departamento de Economia e Sociologia Rural. Surgindo-lhe novas ideias, tratava de implementá-las, tendo como estratégia a conversa sem pressa com todos os colegas de departamento. Não os discriminava. Tinha o dom da argumentação e do convencimento. Volta e meia estava ele convidando e recebendo visitantes do Brasil e do exterior. Estabeleceu a partir dos anos 1970 forte relacionamento com o G. Edward Schuh, que então dirigia a Fundação Ford no Brasil. Da Universidade do Estado de Ohio, manteve fortes laços com diversos professores, como Norman Rask, Dale Adams, Richard Meyer, Donald Larson, entre outros. Era quase uma rotina que o departamento estivesse recebendo professores visitantes, principalmente dos Estados Unidos, mas também de outros países, como Portugal, através da Fundação Calouste Gulbenkian. Com o Prof. Schuh estabeleceu parceria profícua para o resto da vida. Dessa parceria resultou, por exemplo, uma coleção de quatro volumes sobre o desenvolvimento da agricultura, o primeiro de 1973 e o último de $1981^{11}$, coleção essa que passou a ser largamente utilizada nos cursos de pós-graduação de economia agrícola.

Com os professores da Universidade de Ohio, entre outras inciativas, foi concebido e executado, num período de cinco anos a contar de 1969, o Projeto de Formação de Capital, focado na relação entre crédito e crescimento, com o apoio da Usaid. No âmbito do mesmo foi realizado um survey no qual mais de 1.700 questionários - com dezenas de páginas - foram aplicados, em estabelecimentos rurais dos estados de São Paulo, Rio Grande do Sul, Santa Catarina e Minas Gerais. Mais de 250 firmas de insumos e equipamentos agropecuários também foram entrevistadas. Outro survey voltado aos aspectos sociológicos

11. ARAUJO, P. F. C. e SCHUH, G. E. Desenvolvimento da agricultura. São Paulo: Livraria Pioneira Editora, Série Estudos Agrícolas, 4 volumes, 1973-83. 
das mudanças tecnológicas também foi executado. Os questionários foram preenchidos por alunos de graduação e pós-graduação sob supervisão dos professores, em um esforço de coleta de dados em campo com proporções tais, dificilmente verificadas na contemporaneidade. Ainda sobre a envergadura e a qualidade da referida pesquisa, o professor Geraldo Sant'Ana de Camargo Barros lembra que o pagamento pelo preenchimento de um questionário estava condicionado a uma análise procedida por um supervisor (geralmente um professor americano), que o aprovaria somente se a diferença entre receita total e despesa total no fluxo de caixa do estabelecimento, não ultrapassasse 5\%. Caso isso não se verificasse, o aluno deveria voltar ao estabelecimento para sanar esse problema. Os dados levantados por essa pesquisa foram largamente utilizados por estudantes de graduação e de pós-graduação - muitos deles tendo participado dos levantamentos - na elaboração de suas dissertações e outros trabalhos no Brasil e nos Estados Unidos.

O depoente, professor Geraldo Sant'Ana de Camargo Barros, informa que durante esse primeiro período de Paulo Cidade na Esalq ele teria concluído o curso de agronomia e realizado seu mestrado em economia agrária, tendo, inicialmente como orientador o nosso homenageado. Relata que na primeira reunião de orientação foi surpreendido ao ver mais evidências da disciplina e capacidade de organização de Paulo Cidade, que the apresentara uma coleção de projetos de pesquisa que havia preparado para seus eventuais orientados. Cada proposta de projeto continha cerca de uma dezena de páginas devidamente encapadas, detalhando o problema, hipóteses e modelos econômicos a serem estimados. No caso dessa orientação dois deles foram preliminarmente escolhidos para a dissertação. Continuando o relato, diz que Paulo Cidade acompanhava de perto a evolução do texto, dando lições preciosas sobre as técnicas de redação: clareza, precisão, objetividade e extremo cuidado com as normas da língua. Em se tratando de alunos dedicados e interessados, as lições e os ensinamentos recebidos de Paulo Cidade durante a confecção da dissertação, sobre como redigir textos científicos, serviriam para a vida. O depoente informa que, por razões de afastamento de Paulo Cidade do Departamento de Economia, Administração e Sociologia da Esalq, para assumir a direção do Instituto de Economia Agrícola da Secretaria da Agricultura, IEA, do estado de São Paulo, não pôde continuar contando com sua orientação, encerrando os trabalhos de mestrado sob orientação preciosa de Donald Larson, que, ao lado do Prof. Joaquim Engler, contribuiu para viabilizar seu programa de doutorado nos Estados Unidos de 1973 a 1976.

Enquanto docente da Esalq, o Prof. Paulo, mesmo mantendo o vínculo com essa unidade de ensino, assumiu atividades da mais alta relevância fora da universidade como diretor geral do Instituto de Economia Agrícola da Secretaria da Agricultura do estado de São Paulo, diretor do Centro de Estudos de Fertilizantes do Instituto de Pesquisa Tecnológica (IPT) do estado, fundador e diretor da Fundação de Estudos Agrários Luiz de Queiroz (Fealq). Quando à frente da Fealq coordenou o Centro de Pesquisa em Economia Aplicada, que, em 2002, foi transformado no Centro de Estudos Avançados em Economia Aplicada (Cepea). Paulo Cidade, durante sua primeira passagem pela Esalq, também ocupou funções tipicamente administrativas, como ter sido Prefeito do Campus Luiz de Queiroz de 1987 a 1990. Como chefe de departamento inúmeras vezes, liderou os processos de criação do programa de doutorado em Economia Aplicada em 1990 e, em 1998, do curso de graduação em Ciências Econômicas na Esalq. Prof. Paulo sempre acreditou na estratégia de manter a instituição em permanente crescimento, atendendo à demanda existente ou criando demanda nova.

Segundo o Prof. Geraldo, saltava aos olhos o seu profundo gosto pela economia e sua imensa admiração pelos grandes economistas. Numa das salas do departamento postou 
352 - Paulo Fernando Cidade de Araújo: a unanimidade como homem de ciência, construtor institucional e amigo

uma galeria de fotos de dezenas deles e uma vez confidenciou sua predileção por Frank Knight - mais conhecido por formalizar a diferença entre os conceitos de risco e incerteza e atribuir ao lucro o papel de compensar os empreendedores por suportar a inevitável incerteza das condições econômicas. Para esse pensador do econômico, a demanda por liquidez surgiria nesse contexto de imprevisibilidade, mas, chocando-se com Keynes, propunha que a determinação da taxa de juros envolvia o estoque de capital e não o estoque de moeda. No campo filosófico, questionava o que seria a verdade em economia.

Finalizando seu depoimento, o sócio legendário da Sober Geraldo Sant'Ana de Camargo Barros, afirma que Paulo Cidade era, de fato, o que poderia ser chamado de "professor em tempo integral". Mesmo fora das salas de aula, quase sempre cercado de alunos e colegas, estava ensinando, dando lições, expondo seus pontos de vista, incentivando a formulação de projetos de vida e sua realização, quando não, simplesmente, entretendo seus admiradores.

\section{Passagem pelo Instituto de Economia Agrícola, 1972-1977²}

Por convite do Secretário da Agricultura do Estado de São Paulo, Dr. Rubens de Araújo Dias, que havia sido diretor geral do Instituto de Economia Agrícola, IEA, desde sua criação em 1968, Paulo Cidade exerceu a função de diretor geral da Instituição de 1972 a 1977.

Professor Paulo Cidade se tornara uma referência em economia e desenvolvimento agrícola, sobretudo a partir da difusão de seus trabalhos finais de mestrado e de doutorado, An Economic Study of the Demand for Rural Credit e Produtividade do Crédito Rural na Agricultura, respectivamente, e já referidos anteriormente, ambos constantes do repositório do IEA e disponíveis para consulta. Já evidenciava, portanto, larga experiência nas áreas de agronomia e economia na agricultura, com ênfase em desenvolvimento econômico e política agrícola, algumas das principais atribuições do Instituto.

Originário da Esalq/USP, onde passou a ser livre docente a partir de 1981, uma de suas características era a de incentivar a formação de capital humano nas instituições de pesquisa e serviços, inequivocamente o principal valor de uma instituição com o perfil do IEA. Assim que assumiu o cargo de diretor geral, por seu caráter agregador e por sua iniciativa, criou um conselho consultivo com participação dos diretores de divisão e representantes eleitos dos técnicos para que, mediante expressos critérios de mérito e pontuação, todos os funcionários tivessem oportunidade de fazer cursos de aperfeiçoamento e de pós-graduação em várias faculdades no País e no exterior.

Agindo nesta direção, por diversas ocasiões possibilitou a vinda de professores da Ohio State University (USA) para treinamento de pesquisadores e participação em projetos específicos de pesquisas no IEA.

Dentre outros feitos como administrador, diretor geral do IEA, destacam-se: a elaboração, pela primeira vez, do Prognóstico Agrícola de São Paulo, safra 1972/73; o primeiro Prognóstico Centro-Sul do Brasil, safra 1975/76; a participação no projeto do II PND para o Ministério da Fazenda para algumas das principais cadeias de produção agrícola no estado de São Paulo e um acordo permanente de colaboração e assessoria ao Ministério da Agricultura. Mesmo com limitações de tempo decorrentes da função, Paulo Cidade orien-

12. Este segmento do texto recebeu algumas informações dos ex-pesquisadores do IEA, Maria Auxiliadora de Carvalho e Richard Domingues Dulley. 
tou sete trabalhos finais de mestrado e doutorado de pesquisadores do IEA, que realizaram suas pós-graduações na Esalq/USP.

Uma demonstração inequívoca da generosidade e desprendimento de Paulo Cidade foi o apoio pessoal e institucional que deu para elaboração de dois estudos que se converteram na principal colaboração brasileira para abrilhantar a Fifteenth International Conference of Agricultural Economists, realizada em agosto de 1973 na cidade de São Paulo: “Setor Agrícola do Brasil, comportamento econômico, problemas e possibilidades" e "Modernization of Agriculture in the State of São Paulo". O agradecimento dos autores ao gesto de Paulo Cidade de liberá-los em tempo integral para realizar as pesquisas que deram origem às obras não traduz o envolvimento do staff do IEA e do próprio diretor geral na viabilização dos trabalhos e na publicação dos mesmos.

Paulo Cidade é considerado por alguns pesquisadores como o mais destacado diretor do IEA em toda a sua história. Segundo os mesmos realizava reuniões mensais com o corpo técnico para discutir questões e problemas relacionados às pesquisas e, durante sua gestão, não obstante uma atmosfera de controle da vida intelectual decorrente de recomendações dos serviços de informação durante o período autoritário da vida nacional, Paulo Cidade jamais exerceu qualquer tipo de indução ou censura aos temas de pesquisa.

Merece também destaque o fato que Paulo Cidade e sua equipe contribuíram para estabelecer e definir o projeto que resultou nas instalações da nova sede da Secretaria da Agricultura e Abastecimento do Estado de São Paulo (SAA), no bairro da Água Funda, São Paulo, na década de 1970.

\section{Como construtor institucional à frente da Fundação de Estudos Agrários Luiz de Queiroz, Fealq, 1977 e 1992}

Paulo Cidade foi um dos idealizadores e diretor-presidente da Fundação de Estudos Agrários Luiz de Queiroz, Fealq, tipo de organização indispensável no Brasil para auxiliar as universidades públicas, obrigadas pela legislação e pelos tribunais de conta a ter orçamentos e prestações de contas rigidamente aderentes ao ano-fiscal, períodos orçamentários que normalmente não comportam a execução de gastos em projetos plurianuais. Essas entidades têm também flexibilidade de captação e aplicação de recursos, de prestação de contas de acordo com o direito privado etc. Relata nosso homenageado o seu protagonismo em entrevista concedida ao boletim Esalq Notícias (2013), dizendo que em 1977 recebeu do então secretário da Agricultura e Abastecimento do estado de São Paulo, Pedro Tassinari Filho, em mãos, cheque de 30 mil cruzeiros, que veio a ser o capital inicial da Fundação. A iniciativa contou também com o apoio do diretor da Esalq, Salim Simão e dos demais membros do primeiro Conselho Curador: Roberto Cano de Arruda, Dovilho Ometto, Aristeu Mendes Peixoto, Urgel de Almeida Lima, Humberto de Campos e Rubens Valentini.

A Fealq é entidade de direito privado, sem fins lucrativos, fundada em 1976, com objetivo de apoiar programas de desenvolvimento científico, econômico e social da Escola Superior de Agricultura "Luiz de Queiroz", do Centro de Energia Nuclear na Agricultura e outras unidades da Universidade de São Paulo e de instituições públicas e privadas. Administra recursos de projetos de pesquisa, organiza e gerencia cursos, simpósios, seminários, congressos e outros eventos técnico-científicos oferecidos pelas instituições que apoia e também edita livros, anais de reuniões científicas e outras publicações para divulgação de tecnologia. 
354 - Paulo Fernando Cidade de Araújo: a unanimidade como homem de ciência, construtor institucional e amigo

$\mathrm{Na}$ área social oferece bolsas para estudantes e participantes de projetos e colabora em programas de desenvolvimento de bem-estar social para a comunidade do campus da USP em Piracicaba e de outras instituições.

As realizações da Fundação de Estudos Agrários Luiz de Queiroz (Fealq), nestas últimas décadas de existência, foram possíveis graças à visão e ao idealismo de seus primeiros diretores: Paulo Fernando Cidade de Araújo, Joaquim José de Camargo Engler e Iby Arvatti Pedroso. A Fundação destacou-se como apoiadora na realização de atividades de ensino, pesquisa e extensão, nas áreas de ciências agrárias, ambientais e sociais aplicadas, evidenciando seus impactos no âmbito social, promovendo academicamente todos que desenvolveram projetos junto à fundação, dando, assim, sua colaboração para o desenvolvimento do agronegócio brasileiro.

Todos os departamentos da Escola Superior de Agricultura "Luiz de Queiroz" e do Centro de Energia Nuclear da Agricultura fizeram uso do apoio institucional da Fealq para desenvolvimento de projetos. Outras instituições públicas e privadas também recorrem à Fealq para viabilizar projetos de pesquisa, utilizando sua infraestrutura gerencial e administrativa. A Fealq patrocinou, ou mediou, centenas de projetos de pesquisas e de difusão em ciências agrárias, captando recursos junto às principais agências de fomento nacional como: a Financiadora de Estudos e Projetos, Finep, e o Conselho Nacional de Desenvolvimento Científico e Tecnológico, CNPq, e estadual como a Fundação de Amparo à Pesquisa do Estado de São Paulo, Fapesp.

Foram estabelecidos e coordenados pela Fealq, desde 1981, o Centro de Biotecnologia Agrícola (Cebtec), e o Centro de Estudos Avançados em Economia Aplicada (Cepea), os quais têm formulado importantes diretrizes de atuação avançada em tecnologias geradas nos programas de ensino e pesquisa pelos departamentos da Esalq.

Cabe ainda registro que, em decorrência de seu prestígio, a Fealq recebeu, em um gesto de mecenato científico, uma área expressiva para atividades de pesquisa e produção. Trata-se da fazenda Figueira, em Londrina, estado do Paraná, onde estabeleceu uma estação agrozootécnica voltada ao desenvolvimento de projetos de pesquisa com bovinocultura de corte, forragicultura, silvicultura e outras áreas relacionadas com ciências agrárias e preservação ambiental. A fazenda possui um rebanho de bovinos de corte e matas naturais reconhecidas como Reserva Particular de Patrimônio Natural.

Amilcar Baiardi, professor universitário e associado da Sober, relata que foi servidor da Fealq, na função de pesquisador II, do início de 1983 até o final de 1985, tendo sido contratado por Paulo Cidade. O depoente informa que na ocasião teve relação profissional e acadêmica com Paulo Cidade, na discussão e elaboração de propostas de estudos e projetos de pesquisa que a Fealq deveria submeter à apreciação da Finep e outras agências de fomento à ciência e tecnologia, a bancos de desenvolvimento e a órgãos governamentais, secretarias e ministérios. Ainda segundo Baiardi, um traço do perfil de Paulo Cidade que pôde observar durante sua permanência na Fealq foi o empenho, quase obsessão, na formação de recursos humanos. Em relação ao depoente, Paulo Cidade propôs, da forma mais generosa possível, um horário de trabalho flexível e compatível com o semestre acadêmico, para que o servidor pudesse concluir os créditos no doutorado que realizava no Instituto de Economia da Unicamp, sob a orientação do Prof. Tamás Szmrecsányi.

Em 1984, Paulo Cidade pediu-lhe que colaborasse na organização da Conferência Latino-americana de Economia Agrícola, realizada no mesmo ano, em Piracicaba. O Prof. Amilcar Baiardi informou que nesse período, em colaboração com Delmar Marchetti, Marco Pereira e João Gomes Martines, exerceu sua última atividade na Fealq, que foi a elaboração do Diagnóstico Nacional do Programa de Engenharia Agrícola, patrocinado pela 
Finep e pela Embrapa. Após rescisão de contrato com a Fealq, em razão de um convite para trabalhar na assessoria de José Serra na Secretaria de Planejamento durante o governo de Franco Montoro, o depoente diz que continuou, na nova função no governo estadual, a ter contatos frequentes com Paulo Cidade. Nos mesmos discutia as prioridades do governo estadual em termos de intervenções e políticas públicas, cogitando quais poderiam ensejar demandas de estudos e diagnósticos a serem atendidas pela Fealq. Avaliava também possibilidades de defender as propostas orçamentárias encaminhadas pelo Instituto de Pesquisas Tecnológicas, IPT, que também eram de interesse de Paulo Cidade.

Para Baiardi, a passagem de Paulo Cidade pela Fealq é um exemplo ímpar de dedicação. Foram 15 anos de sua vida profissional, período no qual a fundação ampliou e melhorou os serviços prestados. Paulo Cidade tinha, inequivocamente, um perfil de institutional builder.

\section{Impulsionador da agricultura paulista no breve período do Instituto de Pesquisas Tecnológicas (IPT), 1977-1981 ${ }^{13}$}

A atividade exercida por Paulo Cidade no Instituto de Pesquisas Tecnológicas (IPT), que se deu concomitantemente com a direção da Fealq, resultou na criação do Centro de Estudos de Fertilizantes, Cefer, do qual foi diretor. Tratava-se de um centro multidisciplinar que contava com uma equipe constituída por engenheiros químicos, químicos, engenheiros agrônomos especialistas em solos e economistas agrícolas. Dela faziam parte Decio Zylbersztajn, Cesar Soares, Caio Yamaguishi, Aparecida Sanches Fonseca, e outros pesquisadores vindos do IEA. Posteriormente, agregou-se ao grupo José Roberto Mendonça de Barros.

Paulo Cidade soube gerir com competência a aplicação dos recursos do BID-Finep para a criação desse centro de pesquisas e desenvolvimento, $\mathrm{P} \& \mathrm{D}$, e o conduziu nos primeiros anos de atividades. Além de infraestrutura de pesquisa, investiu em capital humano, conseguindo uma dezena de bolsas de doutorado no exterior mediante apoio do Banco Interamericano de Desenvolvimento - Inter-American Development Bank. De relevante na sua passagem pelo Cefer foi a criação do Conselho de Orientação, composto por renomados pesquisadores e policy makers em ciência e tecnologia como José Pelúcio Ferreira, ex-presidente da Finep e ex-secretário de Ciência e Tecnologia do Rio de Janeiro, Shiro Yamazaki, Fernando Penteado Cardoso, industrial e fundador da Manah, entre outros. Foi uma experiência que deu grande impulso à nascente indústria de fertilizantes do Brasil.

\section{Presença na Sober ${ }^{14}$}

Quando a Sociedade Brasileira de Economia, Administração e Sociologia Rural (Sober) foi fundada (19/02/1959), durante a I Reunião Bianual de Economistas Rurais, com a então denominação de Sociedade Brasileira de Economistas Rurais (Sober), o Professor Paulo Fernando Cidade de Araújo já havia concluído sua graduação em Engenharia Agronômica

13. Este período foi enriquecido pelo depoimento de Decio Zylbersztajn, Professor Titular da Faculdade de Economia, Administração e Contabilidade da USP e sócio atuante da Sober.

14. Este segmento do texto contou com a colaboração e depoimento dos sócios Alivinio de Almeida e Eliseu de Andrade Alves (Fundador e Presidente da Sober 1979/1981). 
356 - Paulo Fernando Cidade de Araújo: a unanimidade como homem de ciência, construtor institucional e amigo

pela Universidade Federal Rural do Rio de Janeiro (1956), ingressando, em seguida, nos quadros do Ministério da Agricultura. Contudo, o que era comum entre engenheiros agrônomos, foi atraído pela análise econômica do processo produtivo no campo da agronomia e decidiu, diante da inexistência de pós-graduação em economia, cursar mais um bacharelado, graduando-se em Ciências Econômicas pela Faculdade de Economia e Finanças do Rio de Janeiro, em 1963. Em 1964, como já relatado, após uma rápida passagem pelo Date em Campinas e diante do desempenho em palestra sobre crédito agrícola realizada na Esalq e para a qual fora convidado, aceitou a proposta do professor catedrático Érico da Rocha Nobre, então responsável pela 7ª Cadeira, Economia Rural, para ser docente. Tornou-se então, professor da Escola Superior de Agricultura Luiz de Queiroz/USP, tendo iniciado suas atividades no segundo semestre desse mesmo ano de 1964.

Em decorrência do Convênio Esalq/USP - OSU (The Ohio State University) e Usaid (US Agency for International Development), licenciou-se, menos de dois anos depois, para realizar seu mestrado nos Estados Unidos em Agricultural Economics pela Ohio State University, o que se concretizou entre 1966 e 1967.

A Sober viria a ser plenamente constituída em 23/02/1960, durante a II Reunião de Economistas Rurais do Brasil e a participação de Paulo Cidade nessa Sociedade tem início a partir de final da década de 1960 e início dos anos 1970, muito em função de sua proximidade com alguns dos egrégios fundadores da Sober, entre os quais cumpre destacar: Ruy Muller Paiva, Eliseu Roberto de Andrade Alves, Alcides Guidetti Zagatto e Érico da Rocha Nobre (este, frisa-se, foi seu orientador no Doutorado realizado de 1968 a 1969 na Universidade de São Paulo, com período de co-tutela na Ohio State University).

Segundo os associados da Sober Pery Francisco Assis Shikida e Alivinio de Almeida, dos anos 1970 em diante, Paulo Cidade sempre demonstrou apreço e dedicação pela Sober, participando efetivamente dos seus congressos, da revista de Economia Rural, RER, das suas diretorias (sendo, por exemplo, vice-presidente durante os anos 1987-1989), culminando com o exercício exemplar da presidência nos anos 1991-1993. Nesse contexto, organizou com primor os congressos ocorridos no Rio de Janeiro em 1992 (30를 Reunião, com o tema "Agricultura, Ecologia e Desenvolvimento") e Ilhéus em 1993 (31를 Reunião, com o tema "Desenvolvimento Agrícola e Desenvolvimento Rural"). Durante sua gestão também promoveu a reformulação e a atualização gráfica da Revista de Economia e Sociologia Rural, RESR, novo nome do periódico sustentado pela Sober.

Os vice-presidentes de sua inolvidável gestão foram: Gervásio C. de Rezende, Sonia M. P. Pereira Bergamasso, Aray Miguel Feldens, Erly Cardoso Teixeira e Roberto de Azevedo. Seu diretor secretário foi Elmar Rodrigues da Cruz e o diretor de relações institucionais foi Alivinio de Almeida. Os conselheiros regionais dessa gestão foram: Alfredo K. Oyama Homma, Júnia Rodrigues de Alencar, Mário Miguel Amim G. Herreros e Walter C. Ferreira (representantes da região Norte); Robério Ferreira dos Santos, José Alexandre de S. Menezes, Maria da Conceição S. de Souza e José Valdeci Biserra (Nordeste); Aércio dos Santos Cunha, Manoel Malheiros Tourinho, José Garcia Gasques e Fritz José de B. Barbosa (Centro-Oeste); Guaracy Vieira, Flavio Condé de Carvalho, José Eli Veiga e Oriowaldo Queda (Sudeste); Judas Tadeu G. Mendes, Sérgio Luiz Lepsch, Sebastião H. Pedrosa e Gustavo M. Quessada (Sul).

Sempre irradiando simplicidade, sabedoria e simpatia (uma tríade de atributos que o caracterizou), sua presença na Sober não se ateve somente aos inúmeros trabalhos e cargos por ele exercidos, mas também aconselhando, com propriedade, as novas gerações de soberianos e não soberianos. Buscava, com uma gana insaciável, a internacionalização da Sociedade. Com presença e familiaridade nas principais escolas agrícolas americanas e 
europeias, fruto de suas profícuas "andanças" pelo mundo, trouxe profissionais do mais alto renome para fortalecer as discussões sobre o rural nacional e mundial, abrindo também as portas para que vários professores da academia brasileira pudessem realizar seu doutoramento nas seletas escolas americanas e europeias.

Paulo Cidade tinha a capacidade de atuar em várias frentes, envolvendo-se em cargos de direção e responsabilidades institucionais, sem reduzir sua presença na Sober e sem negligenciar atividades acadêmicas. Um exemplo marcante dessa habilidade se deu quando ocupou concomitantemente a Presidência da Fundação de Estudos Agrários Luiz de Queiroz, Fealq, entre 1977 e 1992 e a Prefeitura do Campus de Piracicaba da Escola Superior de Agricultura Luiz de Queiroz, Esalq/USP, entre 1987 e 1990. Administrador nato e determinado, conduziu ambos os cargos de maneira admirável. De um lado, junto ao Diretor Professor Joaquim José de C. Engler, preocupava-se em dar andamento aos diferentes projetos de pesquisa encaminhados à Fealq pelos docentes da Esalq. De outro, dedicava atenção às demandas administrativas que chegavam à prefeitura do Campus, encaminhadas pelos diferentes departamentos e usuários da Esalq. Junto ao administrador do Campus, Professor Vidal Pedroso de Faria, realizaram uma gestão marcada pela racionalidade e eficiência.

O envolvimento com a Sober e com atividades administrativas, como já lembrado, não distanciou Paulo Cidade das atividades acadêmicas. Na década de 1990, elaborou vários projetos de pesquisa, dentre os quais cabe destacar o submetido ao Banco Mundial, no valor de US\$ 250 mil, cujo objetivo era analisar a formação de capital na agricultura, em 11 regiões brasileiras. O projeto previa, inclusive, a revisita de produtores que haviam sido entrevistados em 1967, num projeto equivalente, conduzido em parceria com a Ohio State University. Diante disso, Paulo Cidade organizou equipes de pesquisadores que se distribuíram de Norte a Sul do País (muitos dos quais soberianos), cobrindo desde locais como Ariquemes (RO) até Carazinho (RS), passando por Cruz das Almas (BA). Não obstante haver decorrido mais de uma década entre as duas visitas, ainda foram encontrados alguns produtores que haviam sido entrevistados na primeira pesquisa. Em um significativo esforço de pesquisa, foram entrevistados, mediante um questionário de 27 páginas, 441 produtores rurais. As perguntas visavam aspectos técnicos, econômicos, financeiros e sociais, relacionados à atividade rural. Dado o escopo desse projeto, várias pesquisas foram ulteriormente desenvolvidas e permitiram a elaboração de inúmeros artigos científicos, dissertações de mestrado e teses de doutorado durante os anos subsequentes, produções estas fortemente reverberadas nos Congressos da Sober.

Em 2004, durante o $42^{\circ}$ Congresso, a Sober delibera pela criação do título "Membro Legendário", cujo escopo foi o de reconhecer publicamente e, com louvor, aquele profissional que se doou não só à Sociedade, mas ao Brasil, fazendo das ciências rurais não somente um exercício de pensamento construtivo, mas uma arte. Foram três os primeiros "Membros Legendários" da Sober, uma dessas honrarias coube ao Paulo Cidade, abrilhantando sua já premiada carreira.

Em 2012, Paulo Cidade participou do "Painel 50 Congressos em 53 anos de existência: a história da Sober"15, expondo, como poucos, a construção da Sociedade Brasileira de Economia, Administração e Sociologia Rural, suas vicissitudes e transformações ao

15. Sala 01 Erly Brandão Painel 3: "50 Congressos em 53 anos de existência: a história da Sober" Coordenador: Prof. Dr. Amílcar Baiardi (UFBA) - Palestrantes/Debatedores: Dr. Eliseu de Andrade Alves (Fundador e Presidente da Sober 1979/1981) - Prof. Dr. Paulo Fernando Cidade de Araújo (Presidente da Sober 1991/1993) e Prof ${ }^{a}$ Dra. Sônia Maria Pessoa Pereira Bergamasco (Presidente da Sober 1995/1997). 
358 - Paulo Fernando Cidade de Araújo: a unanimidade como homem de ciência, construtor institucional e amigo

longo de mais de meio século de trajetória; para os que participaram deste Painel, foi um momento ímpar na trajetória da sociedade.

A última grande homenagem à sua pessoa ocorreu em setembro de 2016, na cidade de Coimbra (Portugal), durante o II Encontro Lusófono em Economia, Sociologia, Ambiente e Desenvolvimento Rural (ESADR), do qual participava junto à uma comitiva de soberianos, liderada pelo então presidente, Prof. Dr. Marcelo José Braga. No momento dessa honraria, na qual foi feita uma concisa, mas notável narrativa, sobre sua vida, Paulo Cidade mostrava um sorriso singular que irradiava serenidade aos que ali estavam. Ao final, disse apenas Muito Obrigado, salientando que essa é uma expressão única de agradecimento que obriga gratidão eterna. A Sober retribuiu com um MUITO OBRIGADO a Paulo Cidade, com o mesmo sentimento de gratidão dito por ele!

\section{Voltando ao Rio de Janeiro, Universidade do Estado do Rio de Janeiro (UERJ) e o Centro Universitário Geraldo Di Biasi, 2002-2009}

Além de muitas outras atividades desenvolvidas ao longo de sua profícua vida profissional e acadêmica, Paulo Cidade foi professor visitante da Universidade do Estado do Rio de Janeiro (UERJ) de 2002 a 2005. Sua experiência acadêmica e colaboração docente em muito contribuíram na consolidação do então recém-criado Programa de Pós-Graduação da Faculdade de Ciências Econômicas. Foi incansável no ensino, na pesquisa e como conselheiro acadêmico, junto à coordenação do programa. Orientou alunos de mestrado, publicou artigos e ajudou na administração do programa.

Durante sua estadia na UERJ, testemunha Léo da Rocha Ferreira, "tive o privilégio de publicar em coautoria com Paulo Cidade, diversos artigos científicos em periódicos, a exemplo de "Economia e Sociedade", "Revista de Economia e Agronegócio", entre outros. A liderança de Paulo Cidade nos mais diversos assuntos acadêmicos foi notável. Um exemplo foi a participação de Léo da Rocha Ferreira junto à Roberta Wanderley da Costa Marques, em um projeto de avaliação econômica do desenvolvimento sustentável em Rondônia - Planafloro, sob a competente coordenação do Professor Paulo Cidade, na área de desenvolvimento agroflorestal e infraestrutura do Programa das Nações Unidas para o Desenvolvimento PNUD (FERREIRA et al., 2006). Na época, diz o depoente Professor Léo Ferreira, "quando fui editor da Revista de Economia e Sociologia Rural da Sober (2003-2007), muito me beneficiei dos conselhos e sugestões de Paulo Cidade. A Revista da Sober deve em muito às sugestões dele recebidas. Ele foi, junto a G. Edward Schuh e Eliseu Roberto de Andrade Alves, pioneiro na obtenção da honraria de Membro Legendário da Sober, eleitos em 2004.

Continua o Professor Léo em seu relato que, em 1992, quando o Professor Paulo Cidade era presidente da Sober, foram pessoalmente convidar o Professor Mário Henrique Simonsen, então diretor da Escola de Pós-Graduação de Economia da Fundação Getúlio Vargas e ex-colega de Paulo Cidade na FEF-RJ durante o bacharelado em economia, para ser o apresentador da Aula Magna na abertura do XXX Congresso Brasileiro de Economia e Sociologia Rural, realizado no Rio de Janeiro. Segundo Léo da Rocha Ferreira, foi uma aula inesquecível.

Ainda nesse período, anterior ao seu retorno a São Paulo, nosso homenageado foi o responsável pelo projeto acadêmico do curso de graduação em Ciências Econômicas do Centro Universitário Geraldo Di Biasi, UGB, em Volta Redonda (RJ). Muitos dos recém-mestrandos de Economia da UERJ foram levados pelo Professor Paulo para ministrar aula 
nessa cidade industrial do Vale do Paraíba. De 2006 a 2009 foi professor de economia e coordenador do curso de Graduação em Ciências Econômicas do UGB.

Nessa ocasião recebeu um convite do Instituto de Economia Agrícola, IEA, do qual fora dirigente, para apresentar os resultados do trabalho "Política de crédito para a agricultura do Brasil: 45 anos à procura do desenvolvimento". O estudo fora elaborado em parceria com os professores José Roberto Mendonça de Barros, Alexandre Lahóz Mendonça de Barros e Ricardo Shirota e apresentado previamente no Hubert H. Humphrey Institute of Public Affairs da Universidade de Minnesota, por ocasião do Simpósio “Toward a Global Food and Agricultural for an Open International Economy", em homenagem ao Professor G. Edward Schuh, em Minneapolis (USA), ocorrido em maio de 2007.

De acordo com pesquisadores que testemunharam a apresentação, a pesquisa retrata a política de crédito agrícola no período 1960-2005 com análise de longo prazo sobre um tema relevante da agricultura e do desenvolvimento econômico num contexto global, o qual sempre se constituiu preocupação de Paulo Cidade. Na opinião de Léo da Rocha Ferreira, o legado do Professor Paulo Fernando Cidade Araújo é inestimável e ele será sempre lembrado por alunos e colegas.

\section{Retorno a São Paulo, Fundação Museu da Tecnologia de São Paulo, FMTSP, 2009-2012}

Entre 2009 e 2012, antes de retornar definitivamente à Esalq, ocasião na qual essa unidade de ensino comemorava um século de ensino de Economia, (1912-2012), Paulo Cidade, mais uma vez, demonstra sua versatilidade e sua capacidade de encarar desafios institucionais. Na condição de Diretor Presidente ad Honorem da Fundação Museu da Tecnologia de São Paulo (FMTSP) - instituição cultural e educativa, sem fins lucrativos, com autonomia administrativa e financeira e criada pela Lei Municipal no 7.456 de 20 de abril de 1970 nosso homenageado concebe mecanismos visando dar sustentabilidade econômico-financeira a essa entidade. Como dirigente, diante de intenções do governo estadual de dar diferente uso ao imóvel ocupado pela FMTSP, propôs iniciativas e mecanismos que viabilizaram a transferência da mesma para as instalações do "Museu Catavento", localizado no Palácio das Indústrias da cidade de São Paulo. Essa transferência afastou o risco de descontinuidade da missão da FMTSP e tornou possível conseguir uma nova sede na qual se deu a fusão dos acervos do Museu Catavento e da FMTSP.

A mudança garantiu a sobrevivência da FMTSP e a continuidade de seu relevante papel, qual seja, estar voltado para a tecnologia em seus mais variados aspectos, desde a realização de pesquisas, estudo das origens das inovações, sua evolução, difusão e incorporação ao mercado, e até mesmo o comprometimento com a discussão e avaliação dos impactos e implicações da tecnologia na sociedade.

A transferência de sede e a fusão durante o governo de José Serra, 2007-2010, viabilizaram a preservação do Museu da Tecnologia de São Paulo, Museutec, principal ativo da FMTSP e dos Centros Contemporâneos de Tecnologia, CCTECs, os quais pretendem contribuir para os seguintes objetivos: 1) Elevação do nível cultural, educacional e tecnológico da sociedade pela compreensão do caminho da tecnologia e sua evolução, alargando horizontes e estimulando a criatividade e a atividade inventiva, principalmente dos jovens; 2) Preservação e difusão do patrimônio tecnológico, histórico e cultural representado pelo acervo; 3) Motivação e interesse da população pela preservação da memória tecnológica do País; 4) Instituição de um espaço cultural novo e diferenciado a serviço da população. 
360 - Paulo Fernando Cidade de Araújo: a unanimidade como homem de ciência, construtor institucional e amigo

Na realização dessa complexa missão, a FMTSP passou a reunir e expor documentos e peças de acervo, real e virtual em segmentos tecnológicos diversos; restaurar e conservar máquinas, aparelhos, instrumentos e equipamentos antigos e contemporâneos; promover, apoiar e realizar pesquisas, estudos e projetos nas diversas áreas da tecnologia; sediar, organizar e promover exposições, mostras e eventos diversos; divulgar novos produtos, processos e invenções e valorizar e apoiar o processo de inovação tecnológica, estimulando a atividade inventiva, principalmente entre os jovens.

Esta experiência pode, aparentemente, sugerir que Paulo Cidade se afastara de sua trajetória acadêmica, mas, a julgar pela relevância da FMTSP no despertar de interesse pela ciência, conclui-se que nosso homenageado se manteve no foco de formar competências em termos de recursos humanos visando o progresso técnico e o desenvolvimento.

\section{Cooperando com a Fapesp}

Com o apoio da Fapesp, Paulo Cidade coordenou dois grandes projetos de pesquisa: o primeiro concluído em 2002 e publicado pela Fapesp em 2004, e o segundo concluído em maio de 2016, com relatório final não publicado na modalidade impressa. Por meio desses projetos de pesquisa, a Fundação buscou avaliar a sua contribuição para o fortalecimento da infraestrutura científica e tecnológica da agricultura paulista e delinear estratégias institucionais para o futuro. Na primeira pesquisa, que resultou na publicação “O Crescimento da Agricultura Paulista e as Instituições de Ensino, Pesquisa e Extensão numa Perspectiva de Longo Prazo", além de uma análise apurada da evolução da agricultura desde os anos 1960, a equipe liderada por Cidade apresentou uma série de sugestões nas áreas de Educação, Extensão, Desenvolvimento Rural e Pesquisa.

A segunda pesquisa, cujo projeto tinha como título "Contribuição da Fapesp ao Desenvolvimento da Agricultura do Estado de São Paulo", foi realizada entre 2012 e maio de 2016 e divulgada oficialmente em mídia digital a partir de 14 de dezembro de 2016, pela Agência Fapesp. Na mesma foi revelado que os projetos da fundação em apoio à agricultura paulista representavam 5\% do investimento anual total da instituição em 1981, evoluindo para 20\% em 2013. A pesquisa retrata a evolução do setor agropecuário no estado de São Paulo entre 1970 e 2014 e, além dos relatórios parciais e final entregues à Fapesp, ensejou quatro publicações com caráter jornalístico pelo mesmo meio, a saber: "Agronegócio paulista apresenta padrão de crescimento balanceado", "Concentração de poder de mercado pode prejudicar o agronegócio paulista", "Produção da agricultura paulista aumenta em mais de $90 \%$ nas últimas duas décadas" e "Investimentos em capital humano e em pesquisa aumentam a produtividade da agricultura".

Nesse esforço envolvendo os dois projetos, Paulo Cidade teve a colaboração de pesquisadores da Esalq/USP, da USP Ribeirão Preto, da Secretaria de Agricultura e Abastecimento do Estado de São Paulo, das universidades Federal de Santa Catarina, UFSC, Universidade Estadual do Oeste do Paraná, Unioeste, e de Brasília, UnB, além das empresas de consultoria MB Associados e MB Agro. Divulgando a segunda pesquisa a Agência de Notícias da Fapesp elaborou um vídeo no qual Paulo Cidade informa as evidências inequívocas do impacto do apoio da Fapesp ao setor agropecuário de São Paulo: cada R\$ 1 investido com recursos públicos em pesquisa, educação superior e transferência de conhecimento (extensão rural) na agropecuária paulista, resulta em um retorno de $R$ \$ 10 a $R$ \$ 12 para a economia do estado, traduzido no aumento do faturamento do setor, ou em uma contribuição de R\$ 5 para o Produto Interno Bruto (PIB) agrícola de São Paulo. No caso específico dos 
investimentos em recursos humanos, as estimativas do modelo empírico estimado sugeriram que para cada real investido na formação de capital humano há um retorno de $R \$ 9,00$ a R \$14,00 sobre o Valor Bruto da Produção agropecuária de São Paulo.

Para a Fapesp, Paulo Cidade teria sido categórico ao afirmar que "os investimentos públicos em pesquisa, educação e extensão na agricultura têm que estar incluídos nas prioridades do estado de São Paulo, em razão de seu alto retorno para a economia e contribuição para o Produto Interno Bruto, PIB, paulista". Ainda segundo a referida Agência de Notícias, os dois projetos foram igualmente essenciais para subsidiar as estratégias da Fapesp no apoio a pesquisas voltadas para o setor.

\section{O Professor Paulo Cidade na sua segunda passagem pela Esalq: o período como Professor Sênior, 2012-2016}

Em 2012, o Professor Paulo Cidade retornou ao Departamento de Economia, Administração e Sociologia da Esalq como Professor Sênior, simbolicamente comemorando um século de ensino de economia agrícola naquela unidade da USP. Além das atividades no departamento, entre 2014 e 2016 o nosso homenageado também foi membro da Coordenação Adjunta de Programas Especiais da Diretoria Científica da Fundação de Amparo à Pesquisa do Estado de São Paulo, Fapesp.

A maior parte das contribuições acadêmicas do Professor Paulo estão relacionadas ao papel da agricultura no desenvolvimento econômico, com destaque para a política agrícola e, mais especificamente, o crédito rural. Neste período, como sênior, o Professor Paulo publicou capítulo de livro, apresentou trabalhos em congressos internacionais e participou de inúmeras bancas examinadoras de teses e dissertações.

Como já referido anteriormente, em companhia de pesquisadores da área pública, sobretudo de universidades, e com apoio de duas empresas de consultoria já citadas, MB Associados e MB Agro, a principal atividade de investigação de Paulo Cidade no período no qual foi professor sênior da Esalq foi a coordenação, por quase quatro anos, da pesquisa voltada para avaliar os impactos do apoio da Fapesp às ciências agrárias, no estado de São Paulo.

Entre os vários produtos acadêmicos que esta pesquisa gerou, como já mencionado, o que obteve mais notoriedade foi a mensuração dos retornos econômicos dos investimentos em recursos humanos e infraestrutura de pesquisa, o que reforçou a imagem do papel da Fapesp. Esses resultados são relevantes para a compreensão do desempenho da agricultura paulista, e para a importância de diversas instituições para a formação de capital humano voltado para o setor. Além do mais, contribuirão não apenas para políticas públicas setoriais que venham a ser implementadas no futuro, mas também para a decisão sobre alocação de recursos em pesquisa, por parte das agências de fomento.

Alguns dos capítulos deste projeto foram apresentados durante o VIII Congresso da APDEA - II Encontro Lusófono em Economia e Sociologia, Ambiente e Desenvolvimento Rural, realizado em setembro de 2016, na Escola Superior Agrária do Instituto Politécnico de Coimbra. Adicionalmente, os principais resultados desse projeto foram também divulgados em um artigo científico no periódico Economistas, Revista do Conselho Federal de Economia (Cofecon), São Paulo, v. 7, n. 19 p. 52-57, março 2016, com o título "Evidências e números de investimentos em capital humano na agricultura paulista", e em um artigo de opinião, publicado pelo jornal Folha de S. Paulo em 29 jul. 2016, p. A3, com o título "Pesquisa científica impulsiona agricultura". 
362 - Paulo Fernando Cidade de Araújo: a unanimidade como homem de ciência, construtor institucional e amigo

Em 2014, a convite da Fapesp, o Professor Paulo Cidade participou do evento Fapesp Week Beijing, e apresentou um seminário com o título "Human Capital and Agricultural Development in São Paulo, Brazil". Entre as principais conclusões do seminário, destacava-se o papel das universidades públicas, da Embrapa e de alguns institutos de pesquisa na formação de capital humano, direcionado para o agronegócio, o que produziu impactos positivos para a economia do estado e do País.

Ainda no rol das atividades acadêmicas do nosso homenageado, em 2015, no $53^{\mathrm{o}}$ Congresso da Sober, foi apresentado o trabalho "A Eficiência Técnica e o Melhoramento Genético do Setor Canavieiro do Estado de São Paulo", tendo o Professor Paulo como um dos autores. Os resultados dessa comunicação mostraram a importância da utilização de sementes melhoradas para o aumento da eficiência técnica do setor e identificaram os municípios mais eficientes do estado de São Paulo na produção de cana-de-açúcar.

As contribuições do Professor Paulo foram além daquelas relacionadas à pesquisa científica. Devido ao seu valioso envolvimento institucional, o Professor Paulo realizou palestras sobre a centenária história do Departamento de Economia da Esalq e sobre a história da Sociedade Brasileira de Economia, Administração e Sociologia Rural, Sober. Ainda com relação à sua contribuição institucional, duas homenagens lhe foram prestadas em 2011: Homenagem aos Fundadores da Fealq: 35 anos, Fundação de Estudos Agrários Luiz de Queiroz (Fealq) e Termo de Reconhecimento: Tributo à Contribuição Acadêmica, USP/Esalq.

Aqueles que com ele conviveram sempre viram no Professor Paulo Cidade grande apreço pelo contato com os alunos, fosse ministrando aulas ou orientando trabalhos científicos e estágios. Sua atuação havia sido homenageada pelos alunos, ao menos em três oportunidades: na denominação do Centro Acadêmico do Curso de Ciências Econômicas da Esalq como Centro Acadêmico Paulo Cidade - CAPC, em 2003; no Pavilhão de Economia, os alunos de pós-graduação denominaram a sala de estudos como Sala de Estudos "Paulo F. Cidade de Araújo" em 2011; e, em 2013, foi escolhido Patrono da Turma de Bacharéis em Ciências Econômicas da Esalq/USP.

Durante o período em que esteve como Professor Sênior do Departamento de Economia, Administração e Sociologia da Esalq, o Professor Paulo Cidade foi também uma referência, um motivador e orientador de seus colegas, especialmente para os mais jovens. Ao escrever um artigo $^{16}$ em homenagem ao Professor Edward Schuh, o Professor Paulo enfatizou as palavras do Professor Terry Roe, da Universidade de Minnesota, de que "ele fez enorme diferença em todas as dimensões da vida". O mesmo pode-se dizer sobre o Professor Paulo Cidade. Sua atuação como professor e pesquisador deixou uma contribuição indelével para a formação de todos aqueles que com ele conviveram e para as instituições nas quais trabalhou.

\section{0 legado $^{17}$}

As contribuições do Professor Paulo Fernando sobre a importância do capital humano e das instituições de ensino, pesquisa e extensão no desenvolvimento da agricultura paulista serão sempre lembradas. Paulo Cidade não se deixou contaminar pela onda produ-

16. ARAÚJO, P. F.C. G. Edward Schuh: o professor-amigo que valorizou para sempre a agricultura brasileira. Revista de Economia e Sociologia Rural, v. 46, n. 3, p. 887-894, jul./set. 2008.

17. Este segmento do texto contou com a colaboração dos professores e empresários Alexandre Lahóz Mendonça de Barros e José Roberto Mendonça de Barros, ex-colegas, ex-aluno e amigos de Paulo Cidade. 
tivista que influenciou parte considerável do mundo acadêmico no Brasil. Sua produção acadêmica não tem relevância pelo número, mas sim pela qualidade e capacidade de influenciar, de impactar a comunidade de estudiosos do mundo agrícola e rural. Embora não tenha se pronunciado a respeito, é provável que tenha concordado como o Manifesto de Leiden ${ }^{18}$, que versa com seus princípios, justamente sobre a controversa questão quantidade versus qualidade.

Na história do pensamento econômico há também vários casos de economistas que se dedicavam a um tema com profundidade e continuidade e dele retirava elementos para sua obra. Um dos casos mais emblemáticos é o de Piero Sraffa (1951), que publicou poucos livros, mas que, com um único texto de 48 páginas sobre a teoria do valor na introdução da obra de David Ricardo, mobilizou dezenas de milhares de pesquisadores em todo o mundo.

Os últimos anos de vida do Professor Paulo Fernando Cidade de Araújo foram dedicados a revisitar o estudo já referido e que se tornou emblemático, "O Crescimento da Agricultura Paulista e as Instituições de Ensino, Pesquisa e Extensão numa Perspectiva de Longo Prazo", publicado pela Fapesp em 2004. Ele o fez mediante outra pesquisa, "Contribuição da Fapesp ao desenvolvimento da agricultura do estado de São Paulo". Ambas as investigações procuraram aprofundar o papel do capital humano e do ensino, pesquisa e extensão no desenvolvimento da agricultura paulista.

Para quem trabalhou e conheceu o Professor Paulo por muitos anos, percebe o quanto esses estudos significaram para ele. O tema se confundia com tudo o que lhe era mais relevante: a importância de desenvolver talentos, de construir instituições de ensino, pesquisa e extensão, de ampliar o bem-estar social, de transformar o meio econômico e social etc. Dedicou sua vida a esses temas. Foi pioneiro nos mesmos pois, contemporaneamente, a teoria do desenvolvimento econômico dá enorme peso à relação entre a qualidade das instituições e a capacidade de crescer, como atestam os trabalhos de Acemoglu e Robinson (2012) resumidos em seu livro seminal.

A coletânea de artigos por ele organizada em parceria com o professor Ed Schuh, englobando diversos aspectos na teoria de desenvolvimento econômico, serviu como matriz teórica para as referidas pesquisas. Foram muitas horas de discussão para construir o argumento sobre o papel das Instituições Paulistas no desenvolvimento de sua agricultura. O ânimo com que o professor Paulo conduzia as discussões, a produção e a leitura do material, mostravam como o tema fazia eco com seus principais valores pessoais. Sua coordenação nessas pesquisas de elevado impacto se deu de maneira irretocável.

A competência em delinear o caminho, alinhar os diferentes estudos, motivar e manter o grupo coeso e assegurar a qualidade do relatório final, evidencia nitidamente os atributos de um grande líder. De maneira ao mesmo tempo firme e serena foi capaz de construir contribuições ao conhecimento, merecedoras de amplo respeito.

Nas palavras de Alexandre Lahóz Mendonça de Barros e José Roberto Mendonça de Barros, "quem teve o privilégio de ter sido aluno, ter trabalhado desde o início da carreira e ter sido parceiro em diversas empreitadas nas décadas de 60, 70, 80 e 90, participar do fechamento de seu ciclo de vida em um estudo por ele coordenado, foi um presente com o qual o professor Paulo nos honrou".

18. Pesquisadores reunidos na $19^{\circ}$ Conferência Internacional de Indicadores em Ciência e Tecnologia (STI, 2014) realizada em setembro de 2014, em Leiden, Holanda, propõem um conjunto de recomendações para orientar sobre o uso de métricas em avaliação da pesquisa. 
364 - Paulo Fernando Cidade de Araújo: a unanimidade como homem de ciência, construtor institucional e amigo

\section{Referências}

ACEMOGLU, D. e ROBINSON, J. A. Why nations fail: the origins of power, prosperity and poverty. New York: Crown Business, 2012.

ARAUJO, P. F. C. G. Edward Schuh: o professor-amigo que valorizou para sempre a agricultura brasileira. Revista de Economia e Sociologia Rural, RESR, Piracicaba, SP, v. 46, n. 03, p. 887-894, jul./set. 2008.

Os 100 anos de economia na ESALQ: 1912 a 2012. Disponível em: <http://www. economia.esalq.usp.br/historico >. Acesso em: 9 abr. 2017.

. Projeto Memória - Encontros de uma vida profissional. ESALQ Notícias, ano 10, n. 34, dez. 2013. Disponível em: <http://www4.esalq.usp.br/acom/sites/www4.esalq.usp. br.acom/files/esalq- noticias/pdf/EN-34>. Acesso em: 10 abr. 2017.

. Contribuição da FAPESP ao desenvolvimento da agricultura do estado de São Paulo. Reportagem da Agência FAPESP com entrevista de Paulo Fernando Cidade de Araújo, Disponível em: <http://www.bv.fapesp.br/pt/auxilios/58252/contribuicao-da-fapesp-aodesenvolvimento-da-agricultura-do-estado-de-sao-paulo >. Acesso em: 8 abr. 2017.

. (Coord.) et al. Contribuição da FAPESP ao desenvolvimento da agricultura do estado de São Paulo. Relatório Parcial, Versão final revisada, ESALQ, Piracicaba, maio de 2016.

. e SCHUH, G. E. Desenvolvimento da Agricultura. Vols. 4. São Paulo: Livraria Pioneira Editora, Série Estudos Agrícolas, 1973-83.

. et al. O crescimento da agricultura de São Paulo e as instituições de ensino, pesquisa e extensão: uma perspectiva a longo prazo. São Paulo: FAPESP, 2004.

BAIARDI, A. O Pensamento Econômico da Sociedade Brasileira de Economia, Administração e Sociologia Rural. In: SZMRECSÁNYI, T. (Org.). Ensaios de história do pensamento econômico no Brasil contemporâneo. Vol. 1. São Paulo: Ordem dos Economistas do Brasil, 2007, p. 257-268.

. O Ensino de História das Ciências Agrárias nas Universidades. In: $52^{\circ}$ Congresso da SOBER, 2014, Goiânia. Anais do 52º. Brasília: SOBER, 2014. Vol. 1. Disponível em: < http:// www.itarget.com.br/newclients/sober.org.br/congresso2012/> . Acesso em: 10 abr. 2017.

FERREIRA, L. R., ARAÚJO, P. F. C. e MARQUES, R. W. C. Avaliação de um projeto de desenvolvimento sustentável em Rondônia. Economia e Sociedade, v. 15, n. 2, 401-408, ago. 2006.

GRAHAM, L. The intellectual strengths of pluralism and diversity. In: GAVROGLU, K. e RENN, J. (Eds.). Positioning the History of Science. Dordrecht, The Netherlands: Springer, 2007, p. 69-71.

SRAFFA, P. Introduction to Ricardo's principles. In: Ricardo's Works, Vol. 1. Cambridge: Cambridge University Press, 1951.

Todo o conteúdo deste periódico, exceto onde estiver identificado, está licenciado sob uma Licença Creative Commons (cc by 4.0) 